figures were usually recorded in the evening. The superiority of $4 \mathrm{mg}$ of salbutamol over the other two treatments was particularly evident when the 6 p.m. and 8 p.m. PEFR readings were compared with the pretreatment data in 11 out of 12 patients.

\section{Discussion}

In this study oral salbutamol, in a dose of $4 \mathrm{mg}$ four times daily, significantly increased the peak expiratory flow rate for up to four hours in outpatients on intermittent corticosteroid therapy. Most of these patients felt subjectively better while on this dose than when on a lower dose regimen or placebo. However, salbutamol in a dose of $2 \mathrm{mg}$ four times daily had no significant advantage over the placebo.

The almost complete failure to show a statistically significant improvement in PEFR at the end of each three-day spell of treatment with prednisolone is not surprising, since all the patients included in the study had been placed on this type of intermittent treatment regimen only because it had previously been shown that they were not liable to develop a recurrence of asthma during the four-day periods without prednisolone. The observation of a significant prednisolone effect in the 8 a.m. recordings for patients on $4 \mathrm{mg}$ of salbutamol is thus not easy to explain. One possible reason is that an effective dose of salbuta$\mathrm{mol}(4 \mathrm{mg}$ ) given the previous evening may have augmented the effect of three days' treatment with prednisolone and produced a further increase in PEFR that was still being substantially maintained at 8 a.m. the following morning. In contrast, those who were not given salbutamol or who received an inadequate dose $(2 \mathrm{mg})$ the previous evening were presumably less well placed to maintain any prednisolone effect during the night, and no such effect was therefore evident in the 8 a.m. figures. The PEFR in all patients with chronic asthma tends to improve later in the day, when differences between the effects of drugs are more difficult to detect than in the morning. This phenomenon might explain why no prednisolone effect was observed in respect of the 6 p.m. and 8 p.m. recordings, even when the 4-mg dose of salbutamol was being given.

This study exemplified some of the problems encountered in long-term clinical trials of bronchodilator drugs. The chief of these is the natural variation of PEFR which occurs during each day, from day to day, and from week to week. As Hume and
Gandevia (1957) pointed out, the apparent efficacy of a bronchodilator is related to the degree of airways obstruction present before it is administered. Thus regular administration of an effective bronchodilator such as salbutamol may serve to accentuate such fluctuations by providing good relief when the asthma is mild and virtually no relief when it is severe. The decrease in PEFR noted in the third and fourth weeks of treatment could reflect natural variations in the severity of asthma. Alternatively, it could represent the beginnings of tolerance to the drug, which has been shown to occur in most patients on long-term treatment with the older oral sympathomimetic drugs.

We conclude from this trial that salbutamol is an effective oral bronchodilator when given for up to four weeks in a dose of $4 \mathrm{mg}$ four times daily to patients with chronic asthma of mild or moderate severity. We have, however, some reservations on whether effective bronchodilatation can be maintained for long periods by this drug or any sympathomimetic agent. A more prolonged trial would be necessary to clarify this point. Side effects were minimal and salbutamol therefore seems to be safe and effective in the dose used in this investigation. We suggest that oral salbutamol can be recommended for use in patients with mild or moderate asthma for periods of up to four weeks.

Our thanks are due to Dr. D. M. Harris, head of medical services, Allen and Hanburys Limited, for providing the salbutamol and placebo tablets used in the trial, to $\mathrm{Mr}$. A. J. Davey for undertaking the statistical analysis, and to Miss Linda Graham for secretarial help.

\section{References}

Brittain, R. T. (1971). Postgraduate Medical fournal, 47 Suppl., p. 11. Choo-Kang, Y. F. J., Simpson, W. T., and Grant, I. W. B. (1969). British Medical fournal, 2, 287.

Choo-Kang, Y. F. J., Parker, S. S., and Grant, I. W. B. (1970). British Medical fournal, 4, 465.

Engelhardt, A., Hoefke, W., and Wick, H. (1961). Arzneimittel Forschung, 11,521 .

Epstein, S. W., Fletcher, C. M., and Oppenheim, E. A. (1969). British Medical Fournal, 1, 223.

Heaf, P. J. D., and Mattila, M. J. (1969). Arzneimittel Forschung, 19, 1927. Hume, K. M., and Gandevia, B. (1957). Thorax, 12, 276

Kamburoff, P. L., and Prime, F. J. (1970). British fournal of Diseases of the

Chest, 64, 46.
Kennedy, M. C. S., and Simpson, W. T. (1969). British fournal of Diseases of the Chest, $\mathbf{6 3}, 165$.

\title{
Use of Diazoxide in Hypertension with Renal Failure
}

\author{
J. E. F. POHL, H. THURSTON
}

British Medical fournal, 1971, 4, 142-145

\section{Summary}

Treatment with intravenous and oral diazoxide was given to a group of 39 patients suffering from severe drug-resistant hypertension associated with renal impairment. Rapid initial and good long-term control of hypertension was achieved in all cases without the production of clinically significant postural hypotension. The side effects of diazoxide, including its diabetogenic effect, were easily controlled. There was a highly signifi-

Manchester Royal Infirmary, Manchester M13 9WL

J. E. F. POHL, B.SC., M.R.C.P., Lecturer in Therapeutics

H. THURSTON, B.SC., M.R.C.P., Lecturer in Medicine cant improvement in renal function in most patients on long-term oral diazoxide therapy.

Diazoxide may have an important place in both the short- and long-term therapy of resistant hypertension, particularly in association with renal damage.

\section{Introduction}

Severe hypertension associated with impaired renal function requires urgent control. This is often difficult to achieve with conventional sympathetic blocking agents. Total resistance to therapy is not uncommon and if a degree of control is established this may be at the expense of disabling postural hypotension and a further reduction in renal function.

Diazoxide is a non-diuretic bendrothiadiazine with well- 
documented hypotensive properties after intravenous injections (Finnerty, 1968). It lowers hypertensive blood pressures mainly by producing generalized vasodilatation owing to a direct relaxant effect on vascular smooth muscle (Naylor et al., 1968; Schmitt, 1968). Intravenous diazoxide has been recommended for the treatment of hypertension complicated by heart failure (Dollery, 1968) or renal failure (Saker et al., 1968). The major disadvantage of prolonged treatment with diazoxide is the development of hyperglycaemia (Dollery et al., 1962; Loubatières, 1966). Hitherto this side effect has limited the use of diazoxide to short courses of intravenous injections (Finnerty, 1968). However, hyperglycaemia has been shown to respond to oral sulphonyl urea therapy by Wolff (1964).

We wish to present our results in the management of hypertensive patients who were ineligible for conventional hypotensive agents because of any of three unfavourable features: severity of hypertension, resistance to conventional hypotensive therapy, and impairment of renal function. Most of our patients suffered from malignant hypertension and had lying and standing diastolic blood pressures about $140 \mathrm{~mm} \mathrm{Hg}$ after full doses of sympatholytic therapy. All our patients presented with diminished urea or creatinine clearances. In about a quarter of them renal failure was critical (urea clearance $<10 \mathrm{ml} / \mathrm{min}$ ). We wish to emphasize in particular that such patients if necessary can be successfully controlled on a longterm basis with oral diazoxide.

\section{Method}

The diagnostic categories of 39 patients (26 males and 14 females) aged 15 to 63 years are listed in Table I. Thirty-one of them were initially treated by the rapid intravenous injection of

TABLE I-Long-term Oral Diazoxide (39 Patients)

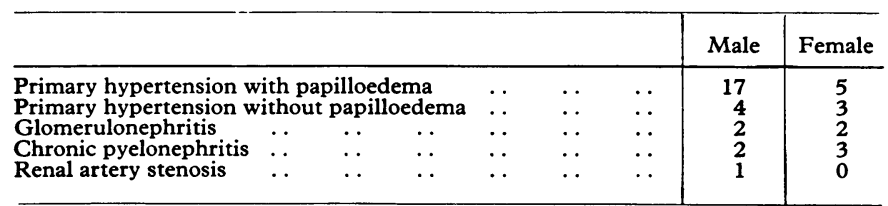

either 300 or $600 \mathrm{mg}$ of diazoxide.* All these were kept flat during the first 24 hours of diazoxide therapy. This precaution was taken to avoid the severe postural hypotension which may result from the interaction of diazoxide with other hypotensive agents previously administered in an unsuccessful attempt to control hypertension, and recently discontinued.

Eight patients were treated with oral diazoxide from the beginning. They were maintained orally on between 50 and $800 \mathrm{mg}$ of diazoxide daily in divided doses. This wide range of dosage was made necessary by the great variation in renal function among the patients.

Each patient was instructed to carry out daily urine testing for sugar with Clinitest tablets. Blood sugar estimations were carried out twice daily during the time spent in hospital and this investigation was repeated at regular intervals during outpatient follow-up. Hyperglycaemia was invariably detected early and was usually controlled with oral tolbutamide and only exceptionally by the injection of soluble insulin. In addition to diazoxide therapy patients were given small doses of methyldopa, debrisoquine, or rarely a $\beta$-adrenergic blocking agent. Sodium retention was treated with daily single doses of frusemide or ethacrynic acid of up to $1 \mathrm{~g}$. Sodium-restricted diets were used only as a last resort. Restriction of dietary protein (Shaw et al., 1965) was practised in the low clearance patients. Diabetic diets were not used, nausea or vomiting was treated with haloperidol or metoclopramide.

\section{Results}

The results of acute intravenous treatment with diazoxide are shown in Table II. The hypotensive effect of each injection occurred almost instantaneously and was maximal within a few

TABLE II-Mean Lying Blood Pressure ( \pm Standard Deviation) before and after Intravenous Diazoxide. The 31 Patients are Grouped according to Pretreatment Diastolic Blood Pressure

\begin{tabular}{|c|c|c|c|c|c|c|}
\hline \multirow{2}{*}{\multicolumn{3}{|c|}{$\begin{array}{l}\text { No. of } \\
\text { Patients in } \\
\text { Group }\end{array}$}} & \multicolumn{2}{|c|}{ Before Diazoxide } & \multicolumn{2}{|c|}{ After Diazoxide } \\
\hline & & & \multirow{2}{*}{$\begin{array}{c}\text { Systolic } \\
248 \pm 34 \cdot 3 \\
245 \pm 18 \cdot 5 \\
228 \pm 17 \cdot 9 \\
216 \pm 41 \cdot 6 \\
234 \pm 19 \cdot 5 \\
195 \pm 20 \cdot 7\end{array}$} & \multirow{2}{*}{$\begin{array}{c}\text { Diastolic } \\
183 \pm 9 \cdot 7 \\
159 \pm 2 \cdot 2 \\
151 \pm 2 \cdot 2 \\
149 \pm 2 \cdot 2 \\
141 \pm 2 \cdot 2 \\
132 \pm 6 \cdot 1\end{array}$} & \multirow{2}{*}{$\begin{array}{c}\text { Systolic } \\
152 \pm 23 \cdot 9 \\
163 \pm 44 \cdot 1 \\
157 \pm 27 \cdot 3 \\
145 \pm 13 \cdot 5 \\
149 \pm 26 \cdot 1 \\
152 \pm 14 \cdot 7 \\
\end{array}$} & \multirow{2}{*}{$\begin{array}{c}\text { Diastolic } \\
96 \pm 9 \cdot 6 \\
90 \pm 14 \cdot 6 \\
102 \pm 8 \cdot 1 \\
98+8 \cdot 4 \\
88 \pm 8 \cdot 4 \\
94 \pm 8 \cdot 6\end{array}$} \\
\hline $\begin{array}{l}5 \\
5 \\
5 \\
5 \\
5 \\
6\end{array}$ & $\begin{array}{l}\because \\
\because \\
\because \\
\therefore\end{array}$ & $\begin{array}{l}\because \\
\because \\
\because \\
\cdots\end{array}$ & & & & \\
\hline & & . & $228 \pm 31 \cdot 0$ & $152 \pm 17 \cdot 0$ & $153 \pm 17 \cdot 0$ & $95 \pm 11 \cdot 5$ \\
\hline
\end{tabular}

minutes. The duration of the effect varied from 1 to 48 hours. The total dose of diazoxide required to produce satisfactory control of the blood pressure varied from $300 \mathrm{mg}$ to $1 \cdot 2 \mathrm{~g}$. Failure to respond was not encountered. Tachycardia and nausea occasionally occurred during intravenous diazoxide therapy. Attempts at blood pressure control by oral diazoxide therapy alone were successful in eight patients, with a reduced incidence of these side effects (Fig. 1).

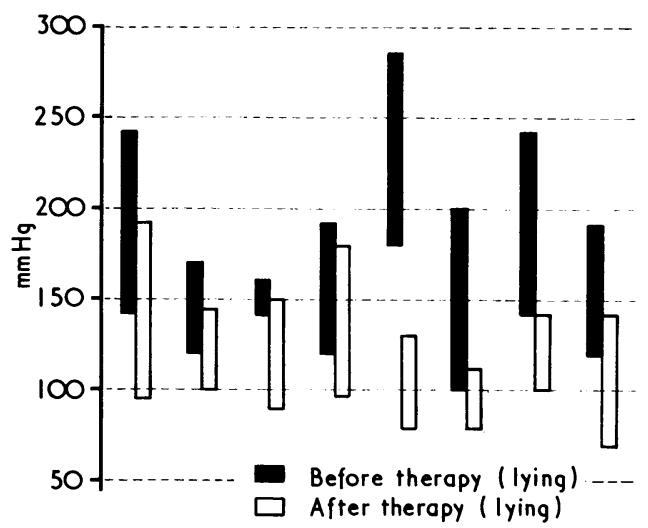

FIG. 1-Acute control of hypertension with oral diazoxide.

By the use of oral diazoxide good long-term control of lying and standing blood pressures was achieved in all 39 patients. Figs. 2 and 3 show the details of blood pressure control of those 20 patients who have been followed for more than three months. The mean blood pressure during diazoxide therapy was calculated as the arithmetical mean of weekly to monthly outpatient readings obtained by us personally. Postural hypotension was no problem, and while frequent adjustments of diazoxide dosage were required in some patients the overall

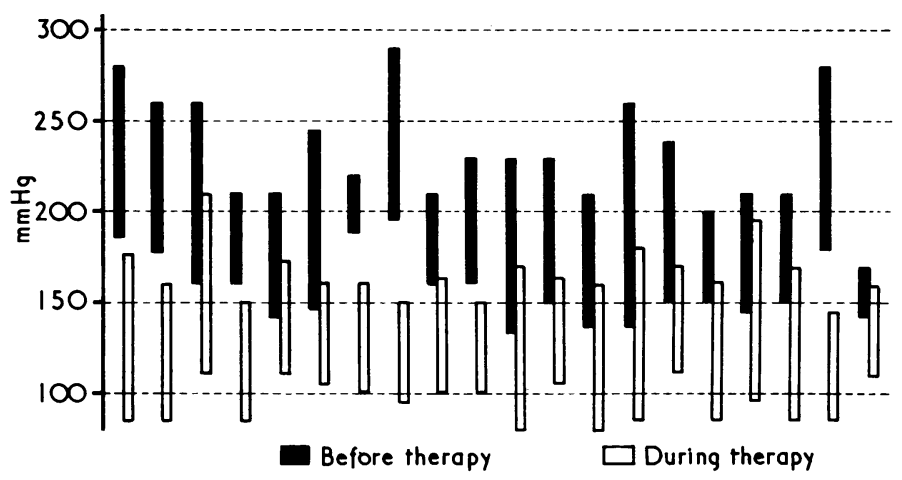

FIG. 2-Lying blood pressure before diazoxide therapy and mean lying blood pressure for each patient during diazoxide treatment. 


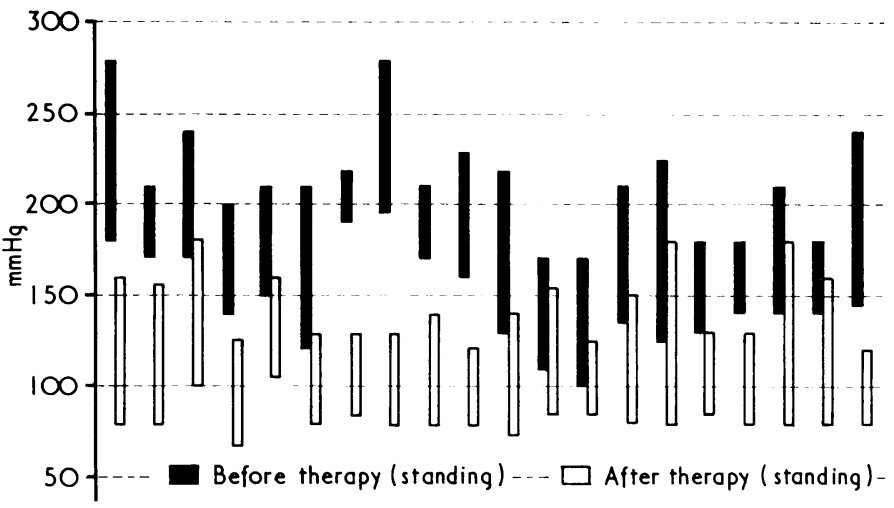

FIG. 3-Standing blood pressure before diazoxide therapy and mean standing blood pressure for each patient during diazoxide therapy.

trend was in the direction of lower dosage-that is, there was no evidence of increasing resistance. The requirement for diuretics and tolbutamide also tended to decrease with time. Details of the incidence and treatment of diazoxide-induced hyperglycaemia in our patients are given in Table III. In all patients the blood sugar levels were maintained at between 50 and $100 \mathrm{mg} / 100 \mathrm{ml}$. No hyperglycaemic crises necessitating hospital admission occurred.

TABLE III-Incidence and Treatment of Diazoxide-induced Hyperglycaemia

\begin{tabular}{|c|c|c|c|c|}
\hline & \multirow{2}{*}{ No. } & \multicolumn{3}{|c|}{ Dose (g/day). Mean \pm S.E. of Mean } \\
\hline & & Initial & Final & Change \\
\hline $\begin{array}{l}\text { Patients never requir- } \\
\text { ing tolbutamide } \\
\text { Patients now off tol- } \\
\text { butamide but re- } \\
\text { quiring it initially } \\
\text { Patients always on } \\
\text { tolbutamide }\end{array}$ & $\begin{array}{c}10 \\
8 \\
21^{*}\end{array}$ & $\begin{array}{l}1 \cdot 1 \pm 0 \cdot 11 \\
1 \cdot 3 \pm 0 \cdot 16\end{array}$ & $\begin{array}{c}0 \\
1 \cdot 0 \pm 0 \cdot 16\end{array}$ & $\begin{array}{l}-1.1 \pm 0.11 P \leqslant 0.0001 \\
-0.3 \pm 0.06 P<0.001\end{array}$ \\
\hline
\end{tabular}

*One patient who initially required insulin is now controlled on glybenclamide $5 \mathrm{mg}$ each morning (therefore excluded from the calculations).

Six of the 39 patients have been treated successfully for over a year. Only three patients died during treatment. Two who died had given up treatment and were no longer receiving diazoxide, both died in renal failure. One woman died of a subphrenic abscess and the two men who died succumbed to myocardial infarctions. Most patients were fit enough to be able to work and lead normal lives. Nausea was troublesome in some patients for several weeks after institution of diazoxide therapy.

Figs. 4 and 5 refer to the renal function data of the 28 survivors who had adequate baseline renal clearance studies. With the exception of one patient with a radiologically established diagnosis of renal artery stenosis there is clear evidence of improvement of renal function during long-term control of

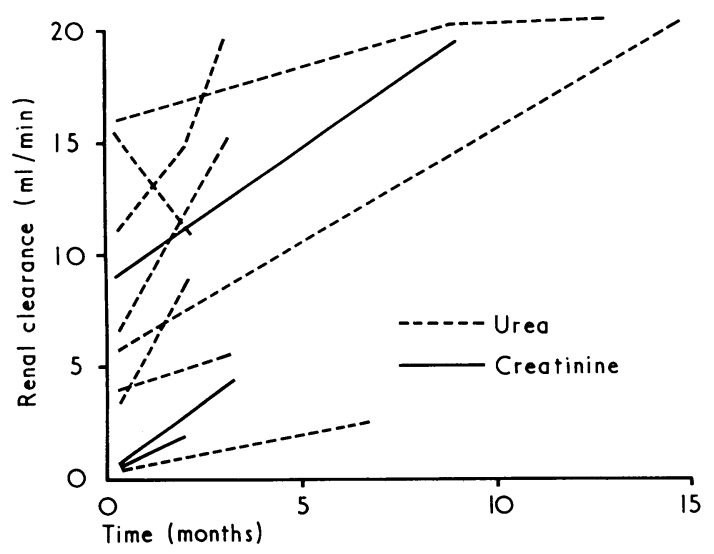

FIG. 4-Low renal function group (clearance $<20 \mathrm{ml} / \mathrm{min}$ ). All but one patient showed improved renal function during treatment.

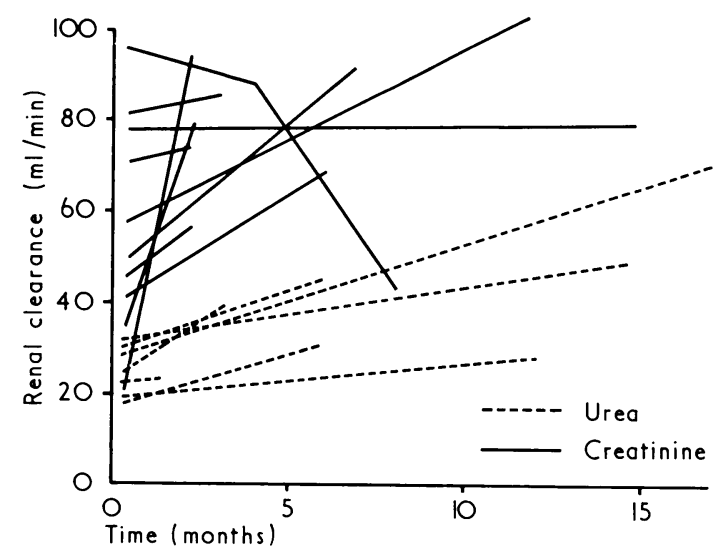

FIG. 5-Patients with higher clearances (clearance $>20$ $\mathrm{ml} / \mathrm{min}$ ) again showed pronounced improvement except one patient who had renal artery stenosis and gout.

blood pressure with oral diazoxide. In three cases improvement from clearances incompatible with survival without dialysis occurred.

The first patient treated with oral diazoxide was a Nigerian woman aged 35 who originally presented with malignant hypertension, blindness, and very severe renal failure. Fig. 6 shows the remarkable improvement of her renal function which occurred during the first two months of treatment with oral diazoxide. With good control of her hypertension her sight gradually recovered. However, soon after discharge from hospital she refused to attend for follow-up and eventually died, totally blind, in left ventricular failure and uraemia nine months later.

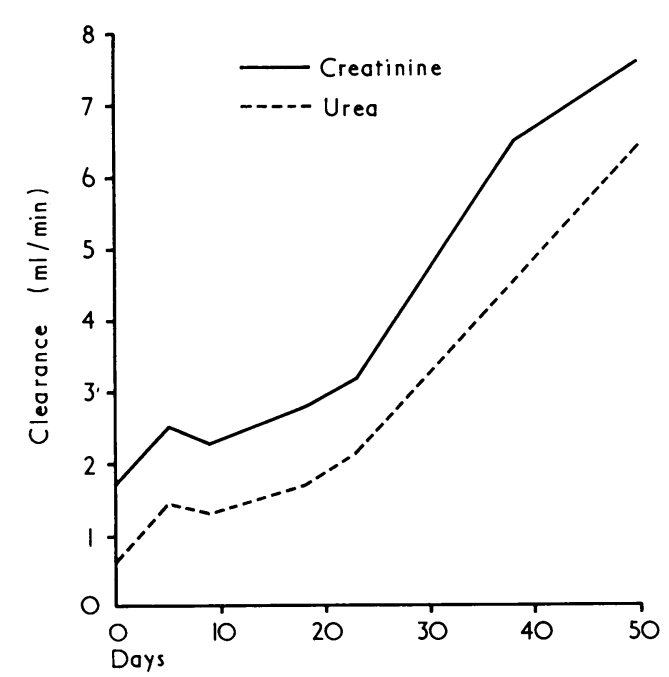

FIG. 6-One patient had a pronounced increase in both urea and creatinine clearance when treated with oral diazoxide for 50 days, after which she gave up treatment.

\section{Discussion}

As Pickering (1968) pointed out malignant hypertension is a therapeutic emergency. If it remains uncontrolled a rapidly fatal outcome can be expected. Mroczek et al. (1969), using repeated injections of intravenous diazoxide, showed that aggressive initial treatment of severe hypertension improves long-term control and renal function. In renal hypertension and in many cases of the malignant phase of essential hypertension ganglion blockers are ineffective and the well-documented rise of blood pressure after intravenous guanethidine (Dollery et al., 1960 ) is also not uncommonly seen after intramuscular guanethi- 
dine. Our patients were resistant to $2 \mathrm{~g}$ of oral methyldopa, up to $150 \mathrm{mg}$ of oral guanethidine, up to $60 \mathrm{mg}$ four times a day of debrisoquine by mouth, and repeated injections of $20 \mathrm{mg}$ of intramuscular guanethidine.

Salt depletion either by peritoneal dialysis or by powerful diuretics-for example, frusemide, ethacrynic acid-may allow the control of severe otherwise drug-resistant hypertension and without doubt many of our patients would have responded to it. Jewkes et al. (1970), however, show that even relatively small doses of frusemide produce a pronounced reduction in renal function commensurate with the reduction in plasma volume and extracellular fluid volume which occurs. Postural hypotension is invariable during pronounced salt depletion, and many patients tolerate it badly. In patients with already critically low glomerular filtration rates (and many of our patients belong to this category) the attempted control of hypertension by salt depletion is not compatible with life without dialysis. The last resource in the treatment of resistant hypertension, bilateral nephrectomy, is also open to this objection (Kolff et al., 1964). As our patients show, intravenous diazoxide provides a means of achieving rapid control of even the most severe cases of hypertension irrespective of the sodium status of the patients and regardless of whether the hypertension constitutes the patients' primary disease or is a complication of renal disease.

Long-term control of severe hypertension with conventional sympatholytic drugs is often unsatisfactory because of the difficulty in producing acceptable supine diastolic pressures without at the same time imposing the burden of crippling postural hypotension on the patient. Total resistance to therapy is not uncommonly encountered after a few months of treatment, especially in renal hypertension. Oral diazoxide produced excellent long-term blood pressure control in our patients without producing a clinically significant postural hypotensive effect. The development of tolerance to its hypotensive action has not been observed by us. We experienced no difficulty in countering its side effects. The diabetogenic effect which in the minds of most physicians has militated strongly against the use of oral diazoxide as a hypotensive treatment was easily overcome by the use of tolbutamide. This allowed us to run our patients on a normal carbohydrate intake with blood sugars consistently in the lower range of normal. We observed a gradual reduction in the tolbutamide requirements of most patients. A few patients were eventually taken off tolbutamide altogether without a recurrence of hyperglycaemia. A possible explanation of this phenomenon is tolbutamide-induced pancreatic cell hypertrophy (Loubatières, 1957; Fajans and Conn, 1960; Loubatières et al., 1963).

The sodium retention caused by diazoxide necessitates at first the use of high doses of frusemide or ethacrynic acid. Mroczek et al. (1969) made a special point of the combination of diazoxide with powerful diuretics to maintain an adequate urine flow during diazoxide therapy of hypertension. We used higher doses of diuretics and obtained higher daily urine volumes from our patients. Tolerance to the sodium-retaining effect of diazoxide usually occurs after some weeks of continuous treatment. It has been our practice not to reduce the diuretic dose very much but to let the patient increase his salt intake. It is significant that the control of hypertension with oral diazoxide was not adversely affected by this.

The almost uniform improvement in renal function that occurred during the treatment of our patients is probably mainly due to the excellence of the blood pressure control which was maintained in all patients during the whole period of treatment. One might speculate that the combination of a fall in blood pressure and increased renal blood flow could have accelerated the healing of the hypertensive renal vascular lesions. It is, however, known that the increased renal blood flow does not raise the glomerular filtration rate per se (Ludens et al., 1968). During long-term treatment it was often possible to reduce the dose of diazoxide without loss of control. This could then be related to the expected regression of hypertensive arteriolar changes once adequate control of the hypertension has been achieved.

We conclude that diazoxide given either intravenously or orally is a uniquely effective therapy of severe drug-resistant hypertension and would seem to be expecially indicated in the presence of diminished renal function. Its side effects are formidable but can be adequately controlled by careful attention to detail during therapy.

\section{References}

Dollery, C. T. (1968). Fourth Symposium on Advanced Medicine, ed. O. Wrong, p. 24. London, Pitman.

Dollery, C. T., Emslie-Smith, D., and Milne, M. D. (1960). Lancet, 2, 381.

Dollery, C. T., Pentecost, B., and Samaan, N. A. (1962). Lancet, 2, 735.

Faians, S. S., and Conn, J. W. (1960). Diabetes, 9, 83. Finnerty, F. (1968). Annals of the New York Academy of Sciences, 150,

Jewkes, R., Burki, N., and Guz, A. (1970). Clinical Science, 38, 439.

Kolff, W. J., Nakamoto, S., Poutasse, E., Straffan, R., and Figueroa, J. (1964). Circulation, 30, Suppl. 2, p. 23.

Loubatières, A. (1957). Diabetes, 6, 408

Loubatières, A., Fruteau de Laclos, C., and Houareau, M. H. (1963). Comptes Rendus des Séances de la Société de Biologie et des ses Filiales, 157, 1652

Loubatières, A. (1966). Comptes Rendus des Séances de la Société de Biologie et de ses Filiales, 160, 1635 .

Ludens, J., Hook, J., Brody, M., and Williamson, H. (1968). Fournal of Pharmacology and Experimental Therapeutics, 163, 456.

Mroczek, Q., Davidov, M., Gavrilovich, L., and Finnerty, F. (1969). Circulation, 40, 893.

Naylor, et al. (1968). American Heart fournal, 75, 223.

Pickering, G. (1968). High Blood Pressure, 2nd edn., p. 450. London, Churchil.

Saker, B. M., Mathew, T. H., Eremin, J., and Kincaid-Smith, P. (1968). Medical fournal of Australia, 1, 592 .

Schmitt, H. (1968). Archives Internationales Pharmacodynamie et de Thérapie 171, 339.

Shaw, A. B., Bazzard, F. J., Booth, E. M., Nilwarangkur, S., and Berlyne, G. M. (1965). Quarterly fournal of Medicine, 34, 237.

Wolff, F. (1964). Lancet, 1, 309. 